\title{
Automatic Classification Method of Quaternary Lithology in Vegetation Cover Area Combining Spectral, Textural, Topographic, Geothermal, and Vegetation Features
}

\author{
Sipeng HAN ${ }^{\text {a }}$, Shuang SHUAI ${ }^{\text {b,c,1 }}$, Wangchuan GUO ${ }^{\text {a }}$ and Peng YANG ${ }^{\text {a }}$ \\ ${ }^{a}$ Research Center of Applied Geology of China Geological Survey, Chengdu \\ 610036, China \\ ${ }^{\mathrm{b}}$ Institute of Geologic Survey, China University of Geosciences (Wuhan), Wuhan \\ 430074, China \\ ${ }^{\mathrm{c}}$ Hubei Institute of Land Surveying and Mapping, Wuhan 430010, China
}

\begin{abstract}
To explore the automatic classification method of Quaternary lithology in vegetation covered areas is significantly helpful to improve the efficiency of Quaternary lithology mapping. Due to the vegetation cover and human modification effects, the traditional lithology identification methods based on image spectra and textures are often challenging to be effective. This paper uses multi-source remote sensing data such as OLI, TIRS, and ASTER GDEM to extract multiple types of spectral (SPEC), textural (TEX), topographic (TOPO), geothermal (TEM), and vegetation (VEG) based on principal component transform, gray co-occurrence matrix, topographic factor calculation, thermal radiation transport model and vegetation index in the Quaternary distribution area of Viet Chi, Vietnam. Remote sensing features were selected and combined to form 16 kinds of classification datasets. The lithological units was automatically classified using the random forest method, The method's accuracy was evaluated to study the effectiveness of multi-type remote sensing features on the automatic classification of Quaternary lithology in vegetation cover area. The results show that the geothermal, textural, and topographic features can effectively improve the lithological classification accuracy, and the overall classification accuracy is improved by $0.32 \%, 0.87 \%$, and $2.25 \%$, respectively, compared with the use of spectral data alone. Among the 16 classification datasets constructed, the dataset combining spectral, textural, topographic, and geothermal features (SPEC+ TEX+ TOPO+ TEM) obtained the highest automatic lithology classification accuracy of $80.99 \%$. This study can provide a technical idea for rapid differentiation of regional Quaternary surface sediment lithologies.
\end{abstract}

Keywords. Quaternary lithology, image classification, spectra, texture, topography, geotherm, vegetation, random forest

${ }^{1}$ Shuang Shuai, Institute of Geologic Survey, China University of Geosciences (Wuhan), Wuhan 430074, China; E-mail: hachsp@163.com. 


\section{Introduction}

Quaternary sediments are geological bodies that are very closely related to human activities and are closely associated with human survival and development [1]. The geological lithological classification of Quaternary sediments is mainly classified and named according to the material grain size [1]. Traditional Quaternary lithology mapping is based on the grid sampling survey combined with an interpolation mapping method [2], which is often time-consuming and labor-intensive. In this paper, we synthesize multi-remote sensing features for the quaternary lithology image classification method to provide an objective reference for carrying out quaternary investigation work, and at the same time, improve quaternary lithology mapping efficiency.

The spectral and textural information of remote sensing data is the most basic information applied to lithology classification. The spectral information of remote sensing data can reflect the combined characteristic differences of selective absorption, reflection, transmission, and scattering of different types of minerals and rocks on the surface to different wavelengths of incident light [3], which in turn can be used to identify mineral and rock categories. Medium spatial resolution sub-remote sensing data (MIRD), such as TM, ETM+ OLI, and ASTER, cover the diagnostic spectral intervals of several types of minerals such as carbonate minerals, clay minerals, and iron oxide minerals [3], and have been widely used for rock and mineral identification. Remote sensing image texture information reflects the spatial variation of radiometric brightness values in the image and is also an important feature used to identify objects. With the use of high spatial resolution remote sensing data (high-resolution data) such as SPOT, QuickBird, WorldView, and GF series, the image texture features can better show the linear tectonic features such as laminations, joints, and fractures in rock strata and the contact relationship between lithological units [4-5], and the improvement of image's spatial resolution is also the most effective way to solve the mixed pixels phenomenon [4]. However, in vegetation-covered areas, rocks and minerals are covered by vegetation, and it is difficult to rely solely on spectral and textural information for lithology identification.

Remotely sensed topographic information provides a quantitative description of geomorphic features [6], while the Quaternary lithology is closely related to the type of geomorphogenesis [7]. Meanwhile, topographic information can reflect the erosion and weathering differences of different lithologies [8], which can assist in the lithological classification of vegetation cover areas. Topographic indices have been widely used in remote sensing lithology classification [6,9]. Othman and Gloaguen combined ASTER spectral, texture, and topographic information for lithology automatic classification and improved the accuracy(73\%-79.3\%) using topographic surface index (SI) [9]. Grebby et al. used airborne LiDAR data to obtain DTM (Digital Terrain Model) data and extracted slope, curvature, surface roughness (SR), and height integral (HI) topographic indices for lithology classification, obtaining an overall classification accuracy of $65.4 \%$ [10]. Most of these studies have focused on lithology classification in bedrock mountains with large topographic relief, and no studies have attempted to classify lithology in the relatively gently topographic Quaternary regions using topographic indices.

Surface vegetation cover remains one of the main factors limiting lithological mapping [11]. The reason is that vegetation cover as low as $10-30 \%$ (e.g., green grass, hay, and lichen) can be sufficient to mask the spectral features of rocks [12]. To solve 
the problem of remote sensing lithology identification in the vegetation densely covered areas, an indirect approach is exploring the geobotanical (geological) relationship between surface vegetation and underlying lithology [13], i.e., to establish correlations between lithology and vegetation types, and then to achieve lithology image classification in vegetation cover areas by identifying the spectral features of specific types of vegetation [14]. Grebby et al. were instrumental in validating Cyprus based on the correlation between vegetation types and lithological units in central Cyprus and completed the lithological classification of vegetation cover areas using airborne hyperspectral data [11]. Amaral et al. verified the correspondence between Quaternary lithology and vegetation types in the Brazilian tropical rainforest region and completed the classification of vegetation types and then lithological image classification using hyperspectral data [15].

The purpose of this study is to verify the validity of remote sensing features such as spectral, texture, topography, surface temperature, and vegetation for the classification of Quaternary lithology in the vegetation cover area and to provide a new way of thinking for carrying out image classification studies of Quaternary lithology in the vegetation cover area.

\section{Study Area and Data Sources}

The study area is located in Viet Chi, Vietnam, in a subtropical region with an average annual temperature above $24^{\circ} \mathrm{C}$ and abundant rainfall. The landform types in the study area are mainly plains and hills, with developed vegetation and large forest cover. The data used are OLI data (figure 1a), TIRS data, and DEM data (ASTER GDEM v2) collected on December 3, 2013.

The stratigraphy of the study area contains Pleistocene-Holocene, and the specific lithological units contain Pleistocene gravels, Holocene sands, Holocene clays, and Holocene gravels, distributed as in figure $1 \mathrm{~b}$.

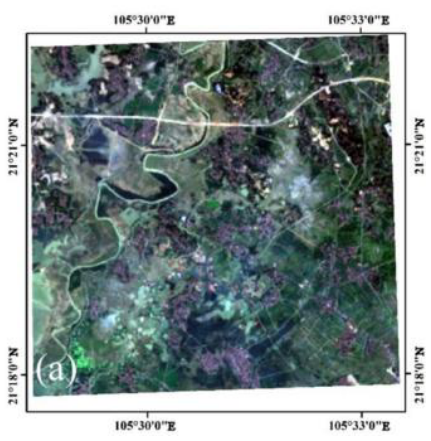

(a) OLI image (432).

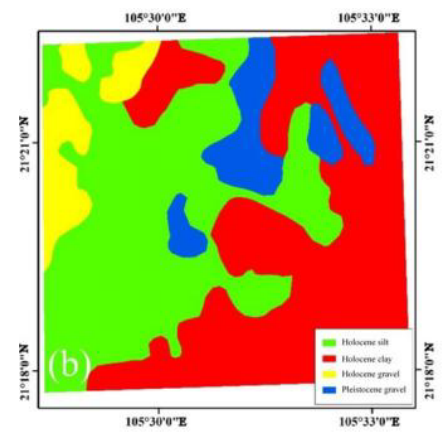

(b) Lithological sketch.

Figure 1. OLI image and Lithological sketch of the study area.

\section{Research Methodology}

In this study, based on OLI, TIRS, and DEM data, we extracted multi-type remote sensing features such as spectral, texture, topography, surface temperature, and 
vegetation using principal component transform, grayscale co-occurrence matrix, terrain factor calculation, thermal radiation transfer model. vegetation index, and so on. We screened and combined these features to obtain a classification dataset of 16 species. For these features, we used automatic lithology classification by using random forest method and evaluated the accuracy. Lastly, we compared and verified the effectiveness of remote sensing features such as spectral, texture, topography, surface temperature and vegetation on the classification of Quaternary lithology in vegetation covered areas.

\subsection{Feature Extraction}

\subsubsection{Vegetation Index}

Vegetation indices extract vegetation features in the study area. Three vegetation indices were selected in this study: Normalized vegetation index (NDVI)reflects the green leaf content of vegetation leaves [16] and has a significant positive correlation with vegetation cover [17]; Greenness and short-wave infrared vegetation index (VIGS), this index response to the stress characteristics of vegetation to heavy metal elements [18]; Short-wave infrared normalized vegetation index (SWVI, SWIR-based normalized difference index); this responds to differences in vegetation foliar water content [19], which is related to vegetation type and growth status.

$$
\begin{aligned}
& \text { VIGS }=w_{1} *(\rho(\text { band } 3)-\rho(\text { band } 4)) /(\rho(\text { band3 })+\rho(\text { band4 }))+w_{2} *(\rho(\text { band5 })- \\
& \rho(\text { band })) /(\rho(\text { band5 })+\rho(\text { band } 4))+w_{3} *(\rho(\text { band5 })-\rho(\text { band6 })) /(\rho(\text { band5 })+ \\
& \rho(\text { band6 }))+w_{4} *(\rho(\text { band5 })-\rho(\text { band } 7)) /(\rho(\text { band5 })+\rho(\text { band })) \\
& \text { SWVI }=(\rho(\text { band5 })-\rho(\text { band6 })) /(\rho(\text { band5 })+\rho(\text { band6 }))
\end{aligned}
$$

$\rho$ is the reflectance of each band, and the weights of the VIGS components were determined according to Hede [18]: w1 $=1.0 ; \mathrm{w} 2=0.5 ; \mathrm{w} 3=1.5 ; \mathrm{w} 4=1.5$.

\subsubsection{Spectral Feature Extraction.}

Due to the information redundancy among OLI reflectance data in each band, the principal component transformation method was applied to compress and enhance the spectral information of OLI images in the study area [20]. And, principal components were selected based on the information content of each principal component and the ability to distinguish lithological units.

\subsubsection{Texture Feature Extraction}

Haralick et al. [21] proposed 14 texture features based on the texture's statistical information of the image using a grayscale co-occurrence matrix. Among them, eight texture features, mean, variance, homogeneity, contrast, dissimilarity, entropy, second moment, and correlation, were often used in lithological classification studies [22-25]. In this study, the above eight statistical parameters were selected to extract the texture images of the study area. In this study, the band5 $(0.865 \mu \mathrm{m})$ with the largest covariance value (919.04) [22,25] was selected for texture calculation for OLI data. Meanwhile, the texture images were extracted according to six window sizes: $3 \times 3,5 \times 5,7 \times 7,9 \times$ $9,11 \times 11$, and $13 \times 13$, and the distinguishability of the lithological units in each 
texture image was compared, and $5 \times 5$ was selected as the window size for texture feature extraction in this study.

\subsubsection{Ground Temperature Feature Extraction}

The surface temperature feature of the study area were extracted based on the TIRS band10 $(10.9 \mu \mathrm{m})$ and the thermal radiative transfer model. Firstly, the MODTRAN atmospheric radiative transfer model was applied to eliminate the atmospheric influence on the surface thermal radiation. Then the surface thermal radiation intensity were revised to the actual surface temperature [26].

\subsubsection{Calculation of Terrain Factor}

Topography results from climate and tectonic interactions [27], while the susceptibility of rock units largely controls terrain to erosion. In this study, four topographic factors, elevation $(\mathrm{H})$, surface roughness (SR), height integral $(\mathrm{HI})$, and surface index (SI), were calculated based on $30 \mathrm{~m}$ spatial resolution ASTER GDEM data and the ability of each topographic factor to distinguish lithological units in the study area was evaluated, where $\mathrm{H}$ is extracted directly from the DEM data, SR is the ratio of the spherical area to the projected area in the grid and is used to quantify the tectonic-geomorphic changes, with higher SR values indicating severe regional deformation. HI is an index used to evaluate the stage of geomorphic development [28,29]. HI values between 0 and 1 indicate erosion processes, where high values indicate undulating mountainous landscapes and low values indicate flat plain landscapes. SI combines the characteristics of SR and HI, with positive SI values corresponding mainly to hard and slightly eroded lithologies, while negative SI values correspond to areas susceptible to erosion [30]. HI and SI are calculated as in equations (3) and (4).

$$
\begin{gathered}
H I=\left(H_{\text {mean }}-H_{\text {min }}\right) /\left(H_{\text {max }}-H_{\text {min }}\right) \\
\mathrm{SI}=\left(\frac{H I-H I_{\min }}{H I_{\max }}\right) *\left(\frac{H-H_{\min }}{H_{\max }}\right)-\left(\frac{S R-\left(1+S R_{\min }\right)}{S R_{\max }}\right)
\end{gathered}
$$

\subsection{Feature Selection and Classification Dataset Generation}

\subsubsection{Feature Selection}

Randomly selected $10 \%$ of the total number of image pixels of each lithological unit as the training samples. These samples were used to evaluate the effectiveness of each extracted remote sensing feature in distinguishing lithological units in the study area, and also participated as training samples in lithological classification. The distribution of vegetation, spectral, texture, temperature and topographic feature values of training samples were obtained separately to compare the ability to distinguish lithological units, as shown in figures 2,3,4. Figure 2 shows that, among the vegetation indices, NDVI has a better ability to distinguish the training image pixels of each lithological unit than VIGS and SWVI. Among the topographic factors, the mean values and values ranges of DEM for Holocene gravels and Pleistocene gravels are significantly larger than those for Holocene clays and Holocene sands; in SR, the mean values and value ranges for Holocene gravels are significantly smaller than those for the other three lithological 
units. Therefore, DEM and SR were selected as topographic factors to participate in the automatic lithological classification. In the surface temperature (TEM), the mean values and value ranges of the Holocene clay are significantly lower than those of the Holocene sand. Figure 4 shows that among the texture features, the variance (VAR), contrast (CON), and dissimilarity (DIS) have the most significant differences in the mean values and value ranges of the training image pixels for each lithological unit.

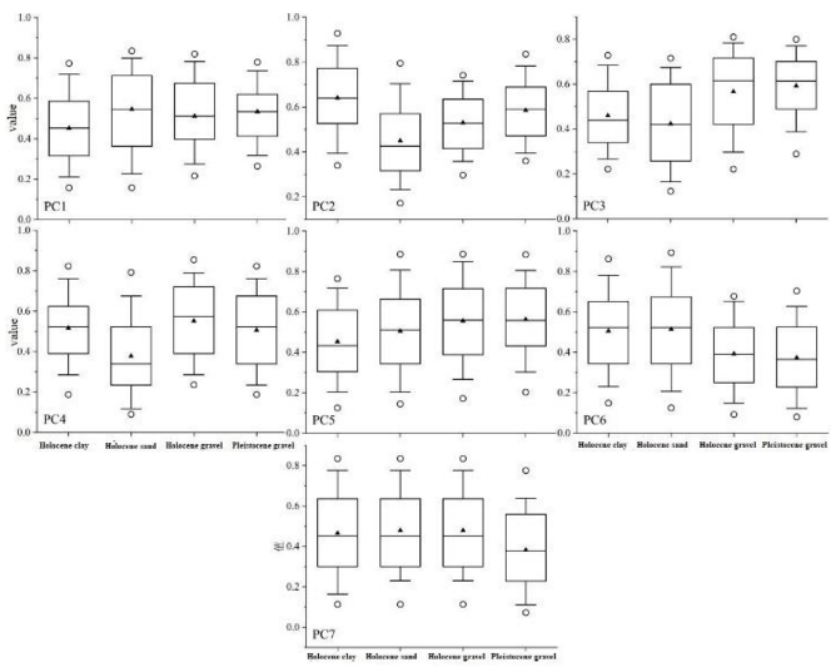

Figure 2. PCs value distributions of the training areas (Each box plots shows the location of the 10th, 25th, 50th, 75th, and 90th percentiles using horizontal lines (boxes and whiskers), the circles are 5th and 95th percentiles, and the triangles are mean values).

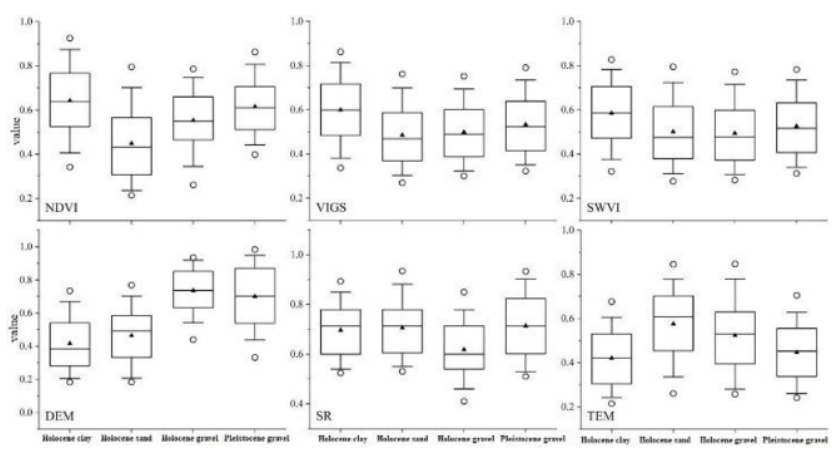

Figure 3. VIs, topography factors, and surface temperature values distributions of the training areas.

\subsubsection{Classification Dataset Generation}

To compare the effectiveness of each remote sensing feature of spectral (SPEC, PC1+PC2 $+\mathrm{PC} 4+\mathrm{PC} 6+\mathrm{PC} 7$ ), vegetation (VI, NDVI+VIGS+SWVI), texture (VAR+CON+DIS), surface temperature (TEM), and topography (TOPO, DEM+SR) on the classification of lithology in the study area, 16 classification datasets (SPEC, SPEC+VI, SPEC+TEX, SPEC+TEM, SPEC+TOPO, SPEC+VI+TEX, SPEC+VI+TEM, SPEC+VI+TOPO, SPEC+TEX+TEM, SPEC+TEX+TOPO, SPEC+TEM+TOPO, SPEC+VI+TEX+TEM, SPEC+VI+TEX+TOPO, SPEC+VI+TEM+TOPO, SPEC+TEX+TOPO+TEM, SPEC+VI+TEX+TEM+TOPO) were constructed based on the spectral features, and other features were added in turn. 


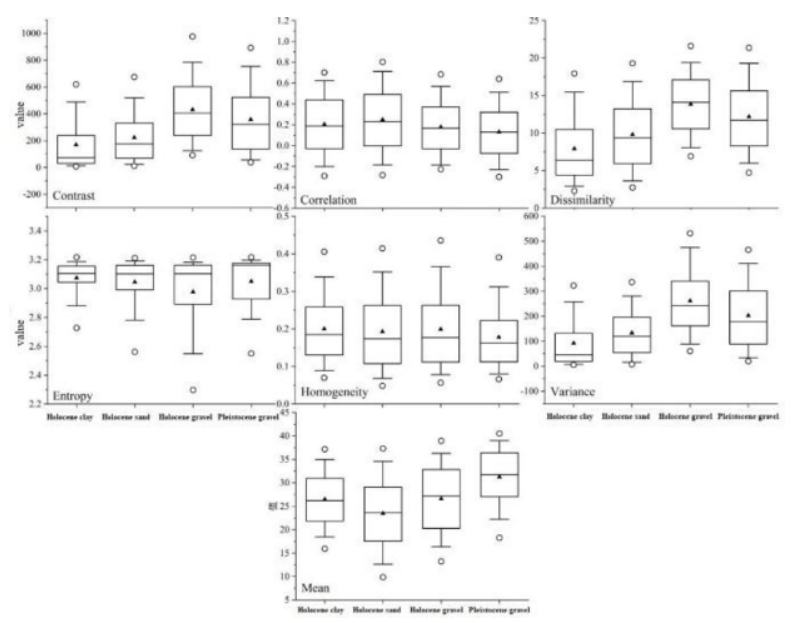

Figure 4. Texture images values distributions of the training areas.

\subsection{Random Forest Classification}

Random forest (RF) image supervised classification algorithm was proposed by Breiman [31], and some scholars have verified the feasibility of its application in lithology classification of hyperspectral and multispectral remote sensing images [6,32]. In this study, 16 classification datasets were used for RF lithology classification experiments. To ensure the objectivity of the comparative experiment, the same training samples and the same number of decision trees (100) were selected from 16 groups of RF lithology classification experiments. Before the classification, Normalized Difference Water Index (NDWI) and Normalized Difference Build-up Index (NDBI) were used to construct masks to eliminate water and construction land interference on lithology classification.

\subsection{Accuracy evaluation method}

A pixel-based classification accuracy evaluation method is used in the study. The confusion matrix method is used to calculate the overall classification accuracy (OA), producer accuracy (PA), user accuracy (UA), and kappa coefficient. The standard reference for accuracy evaluation is the geological map (figure $1 \mathrm{~b}$ ). $90 \%$ of the pixels excluding $10 \%$ of the pixels used as training samples are used as the validation samples to evaluate the accuracy.

\section{Research Results}

The results of accuracy evaluation show that SPEC+TEX+TOPO+TEM has the highest overall classification accuracy and Kappa coefficient, which are 80.99\% and 0.6744 , respectively. While, the overall classification accuracy and Kappa coefficient of SPEC were $77.75 \%$ and 0.6093 , respectively. Among the 4 datasets combining spectral features and a certain other feature, SPEC+TOPO has the highest overall classification accuracy and Kappa coefficient of $80.00 \%$ and 0.6553, respectively; Among the 6 
datasets, combining spectral features and two certain other features, SPEC+TEX+TOPO got the highest overall classification accuracy and kappa coefficient, which were $80.49 \%$ and 0.6646 , respectively; Among the 4 datasets, combining spectral features and two certain other features, SPEC+TEX+TOPO+TEM has the highest overall classification accuracy and Kappa coefficient. The classification accuracy and Kappa coefficient of the classification dataset, including spectral, vegetation, texture, surface temperature, and terrain features, are $80.66 \%$ and 0.6678 , respectively.

The classification results of the four classification datasets of SPEC, SPEC+TEM, SPEC+TEM+TOPO, SPEC+TEM+TOPO+TEX are shown in figure $5(\mathrm{a}, \mathrm{b}, \mathrm{c}, \mathrm{d})$. It can be observed that the misclassification in each lithological unit decreases obviously with the addition of geothermal, topographic, texture, and other features, and the classification effect improvement of Holocene gravel is the most obvious, as shown in table 1 .

Table 1. Confusion matrices of the classification results.

\begin{tabular}{|c|c|c|c|c|c|c|c|c|c|c|}
\hline \multirow{2}{*}{$\begin{array}{l}\text { Classification } \\
\text { data set }\end{array}$} & \multicolumn{2}{|c|}{ Holocene clay } & \multicolumn{2}{|c|}{$\begin{array}{l}\text { Holocene } \\
\text { sand }\end{array}$} & \multicolumn{2}{|c|}{$\begin{array}{l}\text { Holocene } \\
\text { gravel }\end{array}$} & \multicolumn{2}{|c|}{$\begin{array}{l}\text { Pleistocene } \\
\text { gravel }\end{array}$} & \multirow[t]{2}{*}{ OA } & \multirow[t]{2}{*}{ Kappa } \\
\hline & PA & UA & $\mathrm{PA}$ & UA & PA & UA & PA & UA & & \\
\hline SPEC & 92.42 & 73.8 & 76.88 & 85.28 & 8.69 & 87.16 & 38.52 & 73.7 & 77.75 & 0.609 \\
\hline $\mathrm{SPEC}+\mathrm{VI}$ & 91.86 & 73.25 & 76.52 & 84.6 & 8.94 & 89.58 & 36.41 & 72.54 & 77.16 & 0.599 \\
\hline SPEC+TEX & 92.23 & 75.78 & 79.86 & 83.64 & 12.39 & 86.01 & 33.98 & 74.35 & 78.62 & 0.625 \\
\hline SPEC+TEM & 92.08 & 74.51 & 78.68 & 84.8 & 8.34 & 93.36 & 36.64 & 71.79 & 78.07 & 0.615 \\
\hline SPEC+TOPO & 92.33 & 78.03 & 79.12 & 84.22 & 31.61 & 76.3 & 42.25 & 74.47 & 80.00 & 0.655 \\
\hline SPEC+VI+TEX & 91.73 & 75.55 & 79.08 & 83.35 & 14.02 & 85.87 & 35.19 & 71.67 & 78.26 & 0.620 \\
\hline SPEC+VI+TEM & 92.06 & 73.89 & 77.57 & 84.59 & 6.75 & 91.94 & 35.47 & 69.61 & 77.46 & 0.604 \\
\hline SPEC+VI+TOPO & 92.22 & 77.15 & 78.38 & 84.31 & 24.29 & 77.82 & 42.08 & 69.95 & 79.29 & 0.642 \\
\hline SPEC+TEX+TEM & 92.06 & 76.65 & 80.39 & 83.72 & 14.01 & 83.39 & 36.56 & 70.43 & 78.99 & 0.634 \\
\hline $\mathrm{SPEC}+\mathrm{TEX}+\mathrm{TOPO}$ & 92.17 & 79.37 & 80.72 & 83.28 & 31.06 & 76.94 & 42.48 & 74.25 & 80.49 & 0.665 \\
\hline SPEC+TEM+TOPO & 92.48 & 78.55 & 79.44 & 84.23 & 25.81 & 74.43 & 43.76 & 69.49 & 80.00 & 0.656 \\
\hline $\begin{array}{l}\text { SPEC+VI+TEX } \\
+ \text { TEM }\end{array}$ & 92.05 & 76.65 & 80.09 & 83.79 & 14.12 & 88.91 & 37.99 & 69.94 & 79.01 & 0.634 \\
\hline $\begin{array}{l}\text { SPEC+VI+TEX } \\
+ \text { TOPO }\end{array}$ & 92.04 & 79.11 & 80.58 & 83.6 & 28.23 & 77.89 & 43.34 & 71.25 & 80.31 & 0.662 \\
\hline $\begin{array}{l}\text { SPEC+VI+TEM } \\
+\mathrm{TOPO}\end{array}$ & 92.52 & 77.74 & 78.98 & 84.67 & 25.82 & 77.4 & 43.1 & 70.74 & 79.80 & 0.652 \\
\hline $\begin{array}{l}\text { SPEC+TEX+TOPO } \\
+ \text { TEM }\end{array}$ & 92.2 & 80.21 & 81.49 & 83.64 & 30.68 & 77.81 & 45.32 & 72.31 & 80.99 & 0.674 \\
\hline $\begin{array}{l}\text { SPEC+VI+TEX } \\
+ \text { TEM+TOPO }\end{array}$ & 92.36 & 79.67 & 80.92 & 83.9 & 26.28 & 79.5 & 45.35 & 69.87 & 80.66 & 0.668 \\
\hline
\end{tabular}

\section{Discussion}

In this study, the results show that the effectiveness of different remote sensing features for the automatic classification of lithology in the vegetation coverage area is different. The results show that texture, surface temperature, and terrain features can effectively improve classification accuracy. SPEC+TEX+TOPO+TEM achieved the highest overall classification accuracy (80.99\%) and Kappa coefficient (0.6744). Compared with SPEC, respectively, the overall classification accuracy of SPEC+TEX, SPEC+TEM and SPEC+TOPO is improved by $0.87 \%, 0.32 \%$, and $2.25 \%$. It shows that adding topographic factors has the most obvious improvement effect on the accuracy of lithology classification. Lithological units have different topography and landforms. Holocene clay and Holocene sand are mainly distributed in plain areas, while Holocene gravel and Pleistocene gravel are mainly distributed in hilly areas. The classification accuracy evaluation results also show that the producer accuracy of the Holocene 
gravel is significantly improved (increased by $22.92 \%$ ) for SPEC+TOPO compared with SPEC data.

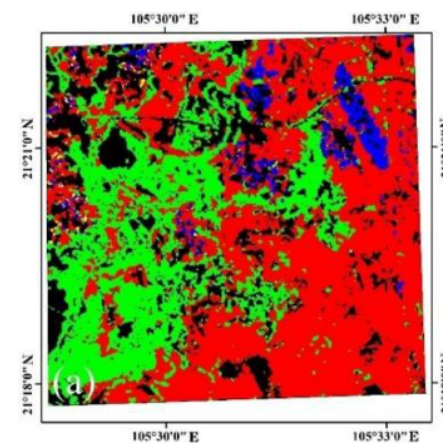

(a) classification of SPEC.

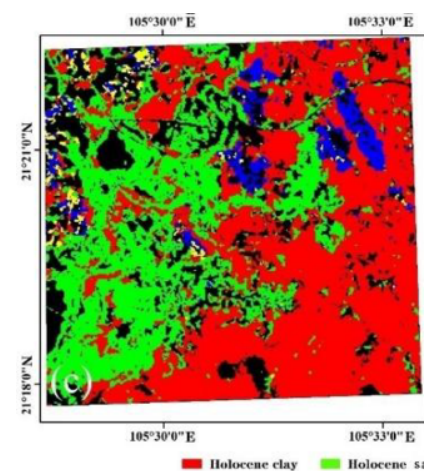

(c) Classification of SPEC+TEM+TOPO.

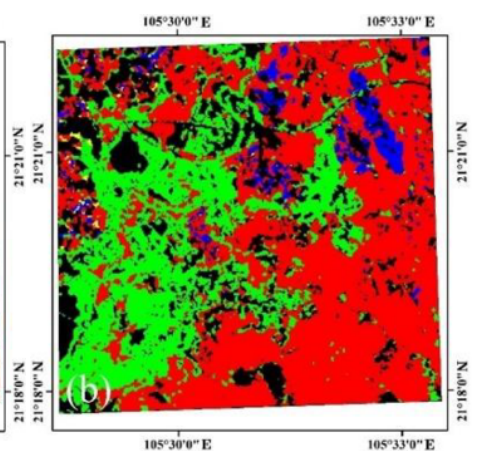

(b) Classification of SPEC+TEM.

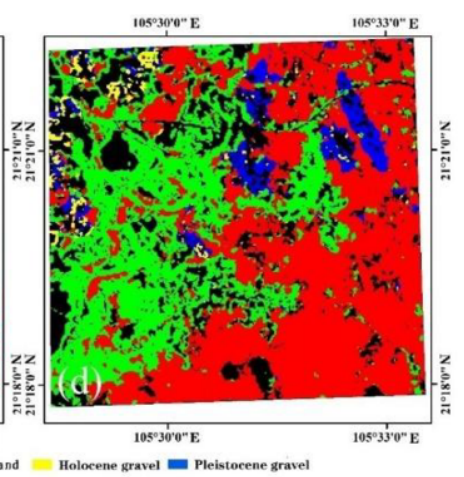

(d) Classification of SPEC + TEM + TOPO + TEX.

Figure 5. Lithological classification results of the study area, using different data sets.

However, we still observed that the classification accuracy of Holocene gravel and Pleistocene gravel is still relatively low, and the highest producer accuracy of each classification data set is only $31.06 \%$ and $45.35 \%$ respectively, which may be related to the low DEM Resolution (30M). Compared with SPEC, the addition of texture features (SPEC+TEX) effectively improves the producer accuracy of Holocene silt $(2.98 \%)$ and Holocene gravel $(3.7 \%)$. The characteristics of surface temperature are helpful to distinguish Holocene clay and Holocene sand. The difference in surface temperature is mainly related to the properties of the underlying surface [26]. The surface temperature of the Holocene clay area in the study area is significantly lower than that of Holocene sand because the water holding capacity of clay is better than that of sand. Compared with SPEC, the addition of surface temperature (SPEC+TEM) can effectively improve the producer accuracy of Holocene sand $(1.80 \%)$ and the user accuracy of Holocene clay $(0.71 \%)$.

In contrast, the addition of vegetation features failed to improve the classification accuracy. Compared with SPEC data, the addition of vegetation features (SPEC+VI) reduces the overall classification accuracy by $0.59 \%$. This may be that vegetation 
characteristics have been included in the spectral characteristics of vegetation, and the addition of vegetation index results in data redundancy. It may also be that the spectral resolution of near-infrared band of OLI data is insufficient to distinguish the difference of vegetation types and growth status effectively. In the next step, we will try to use hyperspectral data to extract vegetation features to assist lithology classification.

\section{Conclusion}

The main conclusions are as follows:

(1) The random forest classification method combined with multi-features proposed in this paper can effectively divide the Quaternary lithology in the study area. The classification data set of spectral + textural + topographic + geothermal (SPEC+TEX+TOPO+TEM) achieves the highest classification accuracy (OA, $80.99 \%$ ); Kappa coefficient, 0.6744). Compared with the spectral data set (SPEC), the overall classification accuracy is improved by 3.24\%, and the Kappa coefficient is improved by 0.0651 .

(2) The results show that the effectiveness of different remote sensing features on lithological classification in vegetation covered areas is different. Terrain features have the most obvious improvement on the classification accuracy of Quaternary lithology in the study area, followed by surface temperature and texture characteristics. While vegetation indexes fail to improve the accuracy of lithology classification.

The automatic classification method of Quaternary lithology proposed in this paper can be further applied to other vegetation covered quaternary areas.

\section{References}

[1] Cai X, Luan Y, Guo G, et al. A study on the sorting of quaternary sediment in the urban geological survey. Urban Geology. 2007 Sep; 2(3): 21-25.

[2] Feng W, Zhang P, Ji W, et al. Geological survey of quaternary superficial sediments and the sedimentary environment of low coastal plain in northern jiangsu: A case study of 1:50 000 geological survey of Wuyou area. Journal of Geology. 2017 Jun; 41(2): 292-296.

[3] Wang R, Xiong S, Nie H, et al. Remote sensing technology and its application in geological exploration. Acta Geologica Sinica. 2011 Oct; 85(11): 1-21.

[4] Xu Y, Meng P, Chen J. Study on clues for gold prospecting in the Maizijing-Shulonggou area, Ningxia Hui autonomous region, China, using ALI, ASTER and WorldView-2 imagery. Journal of Visual Communication and Image Representation. 2019 Apr; 60: 192-205.

[5] Salehi TH, Tangestani M. Large-scale mapping of iron oxide and hydroxide minerals of Zefreh porphyry copper deposit, using Worldview-3 VNIR data in the Northeastern Isfahan, Iran. International Journal of Applied Earth Observation and Geoinformation. 2018 Feb; 73: 156-169.

[6] Othman AA, Gloaguen R. Integration of spectral, spatial and morphometric data into lithological mapping: A comparison of different Machine Learning Algorithms in the Kurdistan Region, NE Iraq. Journal of Asian Earth Sciences. 2017 Jun; 146: 90-102.

[7] Chen Z, Ye Z, Wang Z, et al. Development characteristics and disaster effect of the Quaternary sediments in the middle and upper reaches of the Bailongiang River Basin. Hydrogeology \& Engineering Geology. 2019 Mar; 46(2): 29-36.

[8] Belt K, Paxton ST. GIS as an aid to visualizing and mapping geology and rock properties in regions of subtle topography. Bulletin of the Geological Society of America. 2005 Mar; 117(1-2): 149-160.

[9] Othman AA, Gloaguen R. Improving lithological mapping by SVM classification of spectral and morphological features: The discovery of a new chromite body in the Mawat ophiolite complex (Kurdistan, NE Iraq). Remote Sensing. 2014 Jul; 6(8): 6867-6896.

[10] Grebby S, Cunningham D, Naden J, et al. Lithological mapping of the Troodos ophiolite, Cyprus, using airborne LiDAR topographic data. Remote Sensing of Environment. 2010 Jun; 114(4): 713-724. 
[11] Grebby S, Field E, Tansey K. Evaluating the use of an object-based approach to lithological mapping in vegetated terrain. Remote Sensing. 2016 Oct; 8(10): 1-20.

[12] Ager CM, Milton NM. Spectral reflectance of lichens and their effects on the reflectance of rock substrates. Geophysics. 2012 Feb; 52(7): 898-906.

[13] Paradella WR, Vitorello I. Geobotanical and soil spectral investigation for rock discrimination in the "caatinga" environment (Brazil) based on multitemporal remote sensing data. Canadian Journal of Remote Sensing. 2014 Aug; 21(1): 52-59.

[14] Harris JR, Rogge D, Hitchcock R, et al. Mapping lithology in Canada's Arctic: Application of hyperspectral data using the minimum noise fraction transformation and matched filtering. Canadian Journal of Earth Sciences. 2005 Dec; 42(12): 2173-2193.

[15] Amaral CH do, Almeida TIR de, Souza Filho CR de, et al. Characterization of indicator tree species in neotropical environments and implications for geological mapping. Remote Sensing of Environment. 2018 Jan; 216 (July): 385-400.

[16] Tucker CJ. Red and photographic infrared linear combinations for monitoring vegetation. Remote Sensing of Environment. 1979 May; 8(2): 127-150.

[17] Gutman G, Ignatov A. The derivation of the green vegetation fraction from NOAA/AVHRR data for use in numerical weather prediction models. International Journal of Remote Sensing. 1998 May; 19(8): 37.

[18] Hede ANH, Kashiwaya K, Koike K, et al. A new vegetation index for detecting vegetation anomalies due to mineral deposits with application to a tropical forest area. Remote Sensing of Environment. 2015 Jun; 171: 83-97.

[19] Ji L, Zhang L, Wylie BK, et al. On the terminology of the spectral vegetation index (NIR SWIR)/(NIR+SWIR). International Journal of Remote Sensing. 2011 Nov; 32(21): 6901-6909.

[20] $\mathrm{Wu} \mathrm{Z}$, Ye F, Guo F, et al. A review on application of techniques of principle component analysis on extracting alteration information of remote sensing. Journal of Geo-information Science. 2018 Nov; 20(11): 1644-1656.

[21] Haralick RM, Dinstein I, Shanmugam K. Textural features for image classification. IEEE Transactions on Systems, Man and Cybernetics SMC.1973 Jun; 3(6): 610-621.

[22] Li N, Frei M, Altermann W. Textural and knowledge-based lithological classification of remote sensing data in Southwestern Prieska sub-basin, Transvaal Supergroup, South Africa. Journal of African Earth Sciences. 2011 Jun ; 60(4): 237-246.

[23] Jakob S, Bühler B, Gloaguen R, et al. Remote sensing based improvement of the geological map of the Neoproterozoic Ras Gharib segment in the Eastern Desert (NE-Egypt) using texture features. Journal of African Earth Sciences. 2015 Nov; 111: 138-147.

[24] Qiu Y, Ming D. Lithostratigraphic classification method combining optimal texture window size selection and test sample purification using landsat 8 OLI data. Open Geosciences. 2018 Oct; 10(1): $565-581$.

[25] Masoumi F, Eslamkish T, Abkar AA et al. Integration of spectral, thermal, and textural features of ASTER data using Random Forests classification for lithological mapping. Journal of African Earth Sciences. 2017 May; 129: 445-457.

[26] Bai J, Liu S. Inversion and verification of land surface temperature with remote sensing TM/ETM+ data. Transactions of the CSAE . 2008 Sep; 24(9): 148-155.

[27] Willett SD, Brandon MT. On steady states in mountain belts. Geology. 2002 Feb; 30(2): 175-178.

[28] Pérez-peña JV, Azañón JM, Azor A. CalHypso: An ArcGIS extension to calculate hypsometric curves and their statistical moments. Applications to drainage basin analysis in SE Spain. Computers and Geosciences. 2008 Jun; 35(6): 1214-1223.

[29] Othman AA, Gloaguen R. Automatic extraction and size distribution of landslides in kurdistan region, NE Iraq. Remote Sensing. 2013 May; 5(5): 2389-2410.

[30] Andreani L, Stanek KP, Gloaguen R et al. DEM-based analysis of interactions between tectonics and landscapes in the ore mountains and eger rift (East Germany and NW Czech Republic). Remote Sensing. 2014 Aug; 6 (9): 7971-8001.

[31] Breiman L. Random forests. Machine Learning. 2001 Feb; 45: 5-32.

[32] Bachri I, Hakdaoui M, Raji M, et al. Machine learning algorithms for automatic lithological mapping using remote sensing data: A case study from Souk Arbaa Sahel, Sidi Ifni Inlier, Western Anti-Atlas, Morocco. ISPRS International Journal of Geo-Information. 2019 May; 8(6): 1-20. 